\title{
Left ventricular endomyocardial fibrosis in India
}

\author{
G. VIJAYARAGHAVAN, G. CHERIAN, S. KRISHNASWAMI, \\ AND I. P. SUKUMAR \\ From the Department of Cardiology, Christian Medical College and Hospital, Vellore 632 004, India
}

\begin{abstract}
Clinical, radiological, electrocardiographic, haemodynamic, and cineangiographic features of left ventricular endomyocardial fibrosis are described in 8 patients seen during the 10-year period 1965-1975. Exertional dyspnoea was the commonest presenting symptom. Mild to moderate cardiomegaly was often present. The apex beat was never forcible. A loud third heart sound over the apex and an apical early systolic murmur with late systolic decrescendo were characteristic of this disease. Chest $\mathrm{x}$-ray films showed left atrial enlargement and pulmonary venous congestion. A pronounced rise in left ventricular end-diastolic pressure, severe pulmonary hypertension, and low cardiac index were seen in 6. Ventriculography showed an irregular, poorly contracting left ventricle with areas of dyskinesis and large end-systolic volume. Mitral regurgitation, when present, was not severe.
\end{abstract}

In 1953, following a suggestion from Dr. J. D. Ball, a former staff member of this Institution, a search was made in our necropsy material for endomyocardial fibrosis. Material from 3 cases was later sent to Professor Davies in Uganda, who confirmed the diagnosis. After the publication of this work by Samuel and Anklesaria (1960) necropsy reports of endomyocardial fibrosis were published from various parts of India (Shah et al., 1962; Mehrothra et al., 1964; Kinare and Deshpande, 1965; Reddy et al., 1965; Reddy et al., 1969; Reddy et al., 1970). They described involvement of both ventricles or the left ventricle alone. During a 10-year period (1965 to 1975) we have seen 25 cases of endomyocardial fibrosis. Necropsy data were available from 11 patients and in all of them the left ventricle was involved. There is therefore good evidence of frequent gross anatomical changes involving the left ventricle in patients in India suffering from endomyocardial fibrosis but there has not been any report from this country of the clinical features of left ventricular endomyocardial fibrosis.

\section{Subjects and methods}

During the 10 years from 1965 to 19755100 patients were studied in the cardiac catheterisation Received for publication 29 June 1976 laboratory of this hospital, of whom 12 were found to have endomyocardial fibrosis. In 8 of them the left ventricle was involved, 3 having isolated left ventricular involvement and 5 biventricular endomyocardial fibrosis, and their clinical features are described here. Their ages varied from 7 to 31 years; 6 were male and 2 were female patients. Six of them were students, one a farmer and another an ex-service man. Only 3 of them belonged to the poor socioeconomic group of this country.

The diagnosis of endomyocardial fibrosis was suspected on clinical grounds and confirmed in all by cardiac catheterisation and selective cineangiocardiography. Chest $x$-rays in the posteroanterior view and with barium swallow in the right anterior oblique view were available in all cases. They were carefully examined fluoroscopically to detect intracardiac calcification. Standard 12-lead electrocardiograms were also obtained. Cardiac catheterisation was performed under light sedation with phenobarbitone and promethazine hydrochloride. Pressure data were recorded by means of a Statham $\mathrm{P} 23 \mathrm{Db}$ pressure transducer connected to an Electronics for Medicine 8-channel photographic recorder. Cardiac output was calculated by the Fick principle. Left ventriculography was done in the right anterior oblique view using $1 \mathrm{ml}$ per $\mathrm{kg}$ of 76 per cent Urografin injected under pressure and filming at 36 frames per second. 


\section{Results and analysis}

\section{SYMPTOMS}

Seven patients had progressive exertional dyspnoea, of whom 2 were in severe congestive heart failure. One patient had paroxysmal nocturnal dyspnoea and haemoptysis. A history of vague joint pains at the onset of the disease was reported in 2 subjects. Right hemiplegia was present in a 16-year-old girl (case 4). The youngest of our patients, a 7year-old boy, was brought by his mother (a nurse) who noticed unusual neck vein pulsations. $\mathrm{He}$ was completely asymptomatic.

\section{PHYSICAL SIGNS}

The triad of raised jugular venous pressure, hepatomegaly, and ascites characteristic of right ventricular endomyocardial fibrosis was present in 3 patients. The other 2 patients with biventricular involvement had only a raised jugular venous pressure as evidence of right ventricular involvement. All patients were in sinus rhythm. Case 7, a 31-year-old ex-service man with biventricular involvement, while in hospital, developed atrial fibrillation resulting in pronounced deterioration. The apex beat was well felt in all these patients, but was never forcible. Moderate cardiomegaly was present in 7 patients. Case 5 had a normal sized heart. A moderate left parasternal heave was felt in 5 patients while in 2 others a mild one was present. A palpable second heart sound was felt in the second left sternal border in 5 patients, but none of them had visible or palpable pulsations in that area. The first heart sound was loud in 4 patients. An accentuated pulmonary second sound was present in 6 subjects. A loud third heart sound was audible over the apex in all the 8 patients, while 3 of them had an additional fourth heart sound. All the 5 patients with biventricular involvement had a loud right ventricular third heart sound over the tricuspid area and epigastrium, with a pansystolic murmur of tricuspid regurgitation in 2 of them. An apical early systolic murmur with late systolic decrescendo was heard in 6 of our patients. Crepitations over lung bases were heard in 4 patients.

\section{RADIOLOGICAL SIGNS}

Plain $x$-ray films of the chest closely resembled those of patients with rheumatic mitral stenosis (Fig. 1). There was mild to moderate left atrial enlargement and dilated prominent superior pulmonary veins in all the patients. Pronounced hilar clouding and septal lines were noticed in 3 of them. Even though significant pulmonary hypertension was detected during catheterisation in 6 patients, none showed the expected degree of dilatation of the main pulmonary artery or its primary divisions. Only 1 of the 5 patients with biventricular involvement had a large right atrium. Others had only mild to moderate right atrial enlargement even though the right atrial pressure was very high. Diagnostic ventricular calcification was present in 3 patients and was extensive, involving both ventricles, in 2 of them (Fig. 2).
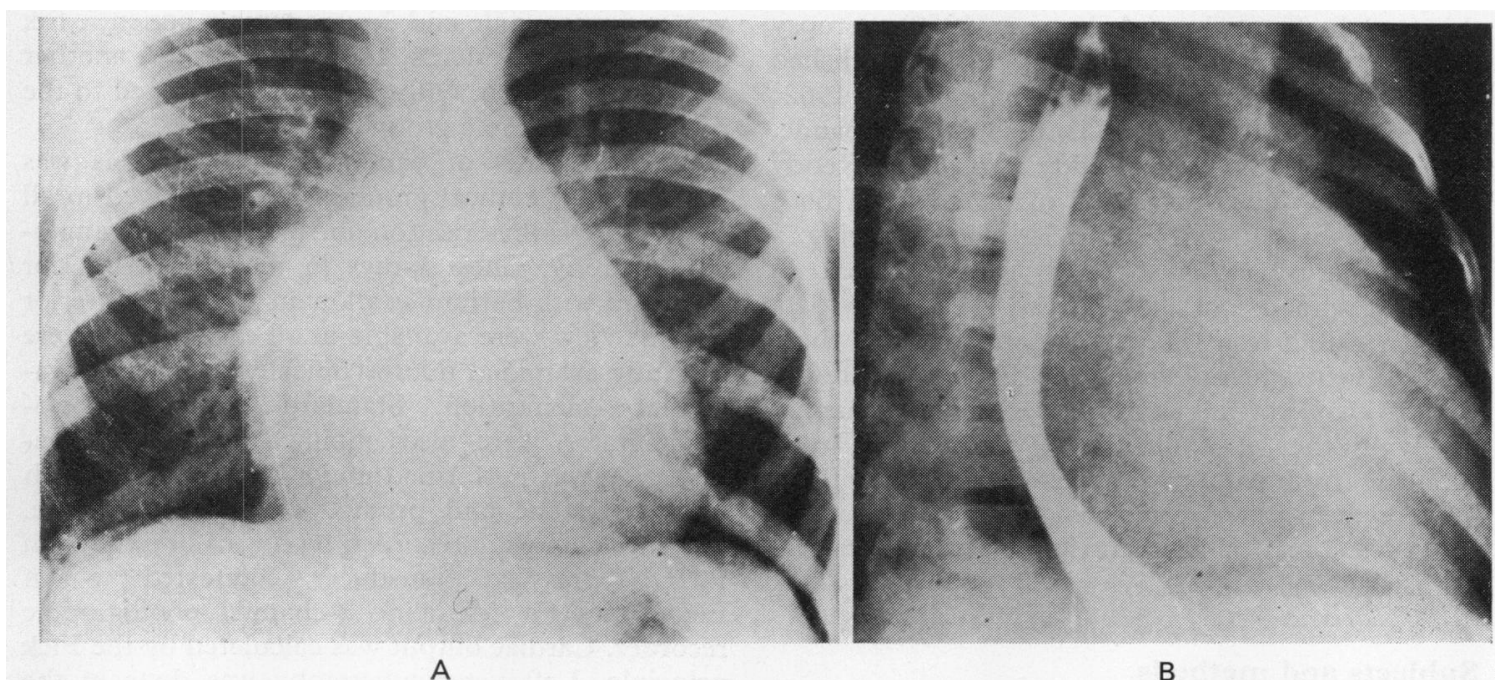

B

Fig. $1 \mathrm{X}$-ray film of chest (case 2). (A) Posteroanterior view showing perihilar venous congestion. The main pulmonary artery is not prominent despite the pulmonary artery pressure of $62 / 32 \mathrm{mmHg}$. (B) Right anterior oblique view with barium showing moderate left atrial enlargement. 


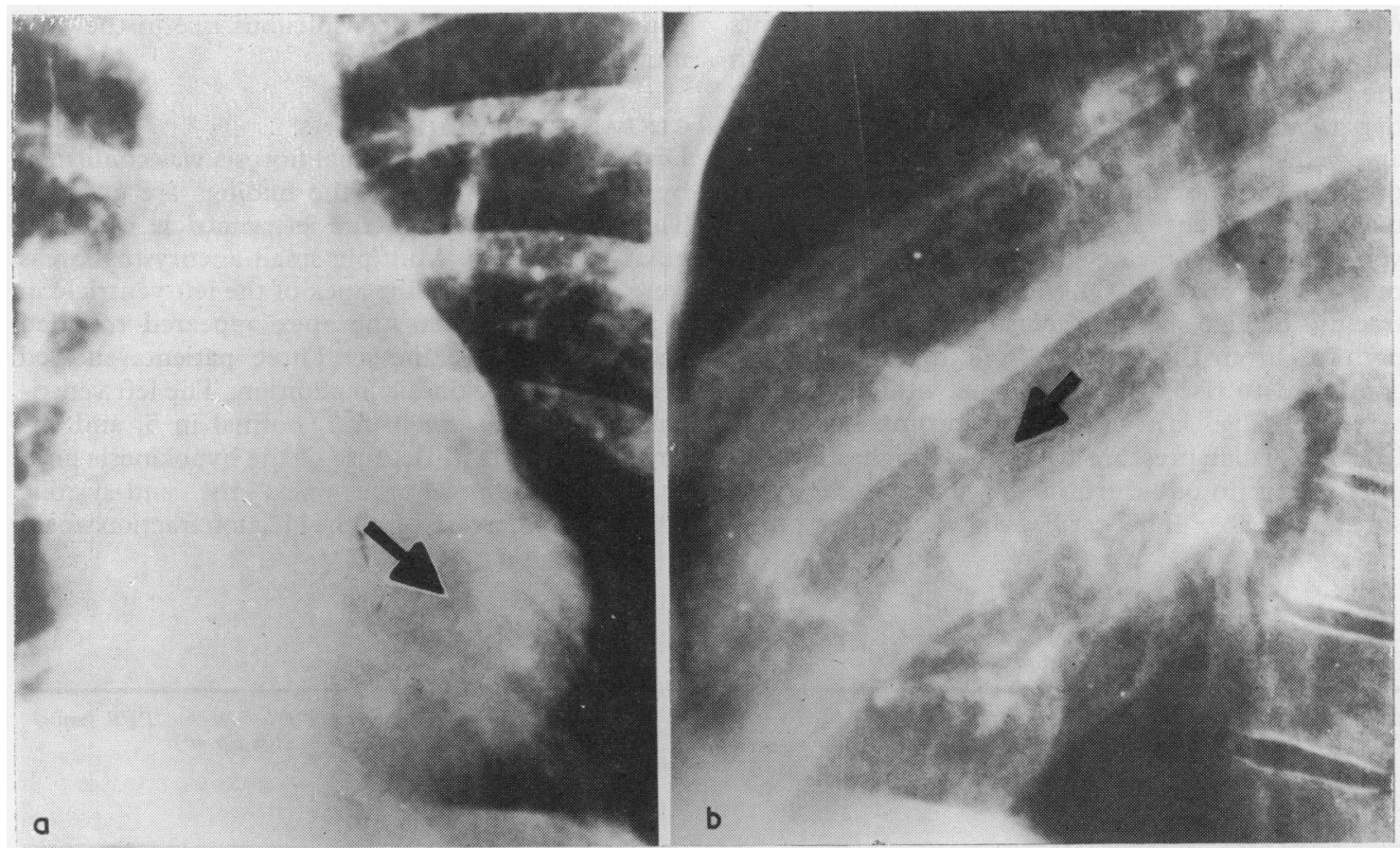

Fig. 2 Plain $\mathrm{x}$-ray film of the chest (case 7). (a) Posteroanterior and (b) lateral views showing extensive intracardiac calcification. Note also enlarged left atrial appendage in posteroanterior view.

\section{ELECTROCARDIOGRAPHIC SIGNS}

All patients showed left atrial $P$ waves and one had evidence of right atrial enlargement in addition. Two had left axis deviation and both had extensive left ventricular calcification. Only 2 patients had evidence of left ventricular hypertrophy.

\section{CARDIAC CATHETERISATION FINDINGS}

Table 1 summarises the right and left heart catheterisation data. All the 5 patients with biventricular endomyocardial fibrosis showed a raised right atrial pressure and right ventricular end-diastolic pressure characteristic of right ventricular involvement.

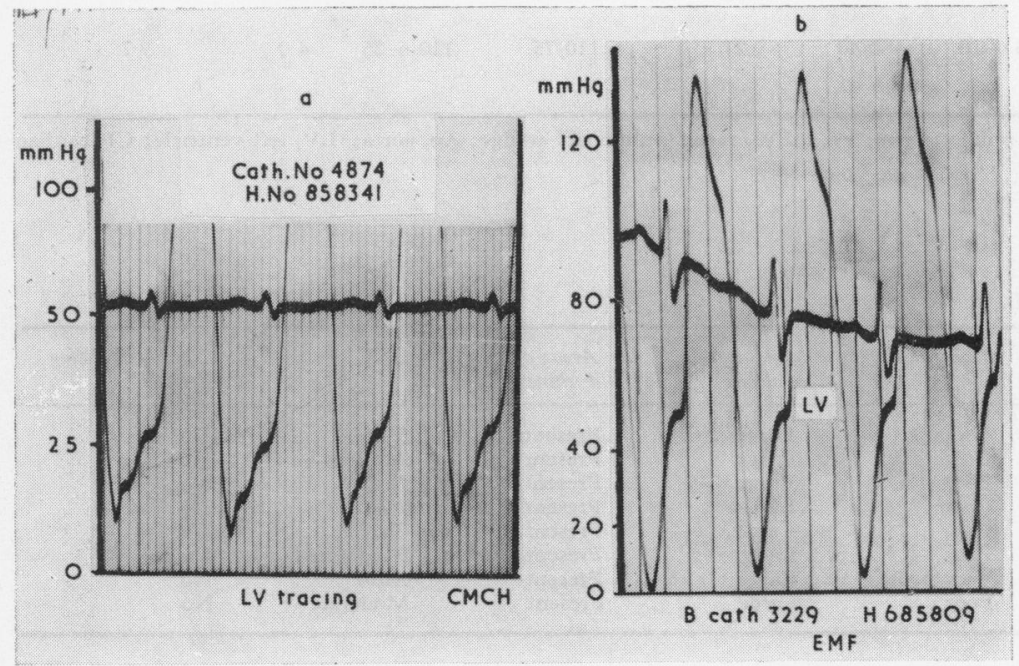

Fig. 3 (a) Left ventricular pressure tracing showing raised early diastolic pressure and gradual rise of pressure till end diastole. Note that the pressure does not come to a 'plateau' in mid or late diastole. (b) Left ventricular pressure tracing. End diastolic pressure (45 $\mathrm{mmHg}$ ) is more than one-third the peak systolic pressure. 
Mean right atrial pressure was normal in patients with isolated left ventricular involvement. With the exception of Case 5, all others had pulmonary hypertension with pronounced rise in the pulmonary wedge pressure. Left ventricular end-diastolic pressure was raised in all of them and none had any diastolic gradient across the mitral valve. Left ventricular dip or early diastolic pressure was also raised in all of them. The left ventricular pressure tracing did not show the diastolic dip and plateau pattern. From the early diastolic dip the pressure continued to rise till end-diastole without forming a plateau (Fig. 3a). It was not uncommon for the left ventricular pressure to reach as high a level as one-quarter to one-third of the peak systolic pressure (Fig. 3b). The cardiac index was low in 6 patients. There was a conspicuous rise in the pulmonary vascular resistance.

\section{CINEANGIOGRAPHIC SIGNS}

Diagnosis of endomyocardial fibrosis was confirmed by ventriculography and the findings are given in Table 2. The shape of the left ventricle was irregular in all cases. Multiple small aneurysmal areas were present around the apex of the left ventricle in 3 patients. In others the apex appeared rounded and showed hypokinesia. Three patients showed generalised hypokinesia in addition. The left ventricular cavity was small in 2, normal in 5, and enlarged in 1 patient. Because of the hypokinesia and/ or aneurysms over the apex, the end-systolic volume was increased and the ejection fraction small.

Table 1 Cardiac catheterisation data

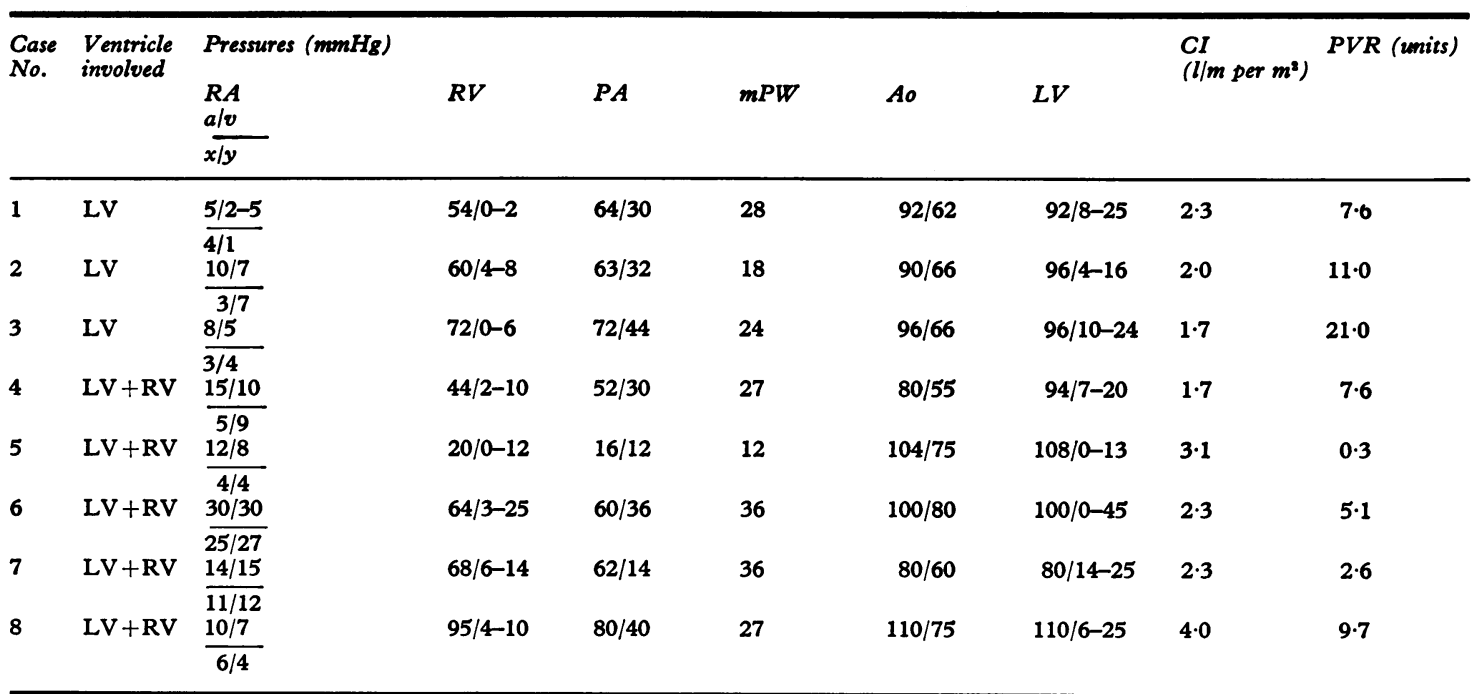

RA, right atrium; RV, right ventricle; PA, pulmonary artery; $\mathrm{mPW}$, mean pulmonary wedge; Ao, aorta; LV, left ventricle; CI cardiac index; PVR, pulmonary vascular resistance.

Table 2 Left ventriculographic signs

\begin{tabular}{|c|c|c|c|c|c|c|c|}
\hline $\begin{array}{l}\text { Case } \\
\text { No. }\end{array}$ & Size & Shape & Contractility & $\begin{array}{l}\text { End-systolic } \\
\text { volume }\end{array}$ & $\begin{array}{l}\text { Areas of } \\
\text { dyskinesis }\end{array}$ & $M R$ & $\begin{array}{l}\text { Thrombus filling } \\
\text { defect }\end{array}$ \\
\hline $\begin{array}{l}1 \\
2 \\
3 \\
4 \\
5 \\
6 \\
7 \\
8\end{array}$ & $\begin{array}{l}\text { Enlarged } \\
\text { Normal } \\
\text { Small } \\
\text { Normal } \\
\text { Normal } \\
\text { Normal } \\
\text { Normal } \\
\text { Small }\end{array}$ & $\begin{array}{l}\text { Irregular } \\
\text { Irregular } \\
\text { Irregular } \\
\text { Irregular } \\
\text { Irregular } \\
\text { Irregular } \\
\text { Irregular } \\
\text { Irregular }\end{array}$ & $\begin{array}{l}\text { Poor } \\
\text { Poor } \\
\text { Poor } \\
\text { Poor } \\
\text { Fair } \\
\text { Poor } \\
\text { Very poor } \\
\text { Poor }\end{array}$ & $\begin{array}{l}\text { Large } \\
\text { Large } \\
\text { Large } \\
\text { Large } \\
\text { Large } \\
\text { Large } \\
\text { Large } \\
\text { Large }\end{array}$ & $\begin{array}{l}\text { Present } \\
\text { Present } \\
\text { Present } \\
\text { Present } \\
\text { Present } \\
\text { Present } \\
\text { Present } \\
\text { Present }\end{array}$ & $\begin{array}{l}\text { Trivial } \\
\text { Mild } \\
\text { Mild } \\
\text { Mild } \\
\text { Trivial } \\
\text { Moderate } \\
\text { Mild } \\
\text { Moderate }\end{array}$ & $\begin{array}{l}\text { No } \\
\text { No } \\
\text { No } \\
\text { No } \\
\text { No } \\
\text { Large } \\
\text { No } \\
\text { No }\end{array}$ \\
\hline
\end{tabular}

MR, mitral regurgitation. 


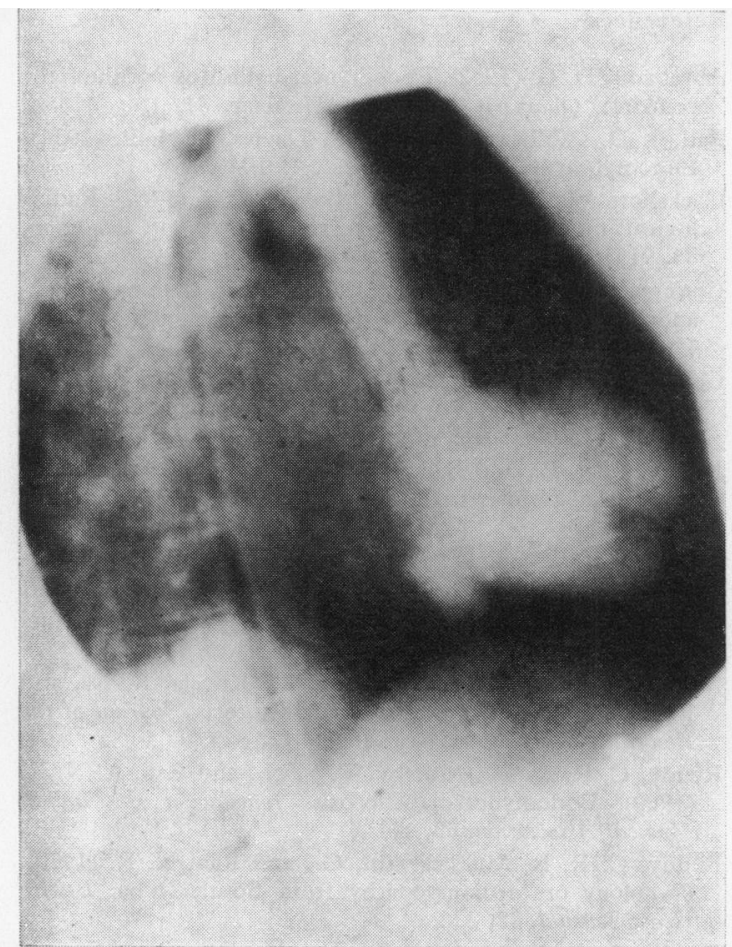

Fig. 4 Left ventriculogram showing irregular chamber and mild mitral regurgitation.

The cavity of the left ventricle appeared smooth and filling defects resulting from papillary muscles were not clear. A distinct mitral valve crescent in diastole was seen only in 3 ventriculograms; in the other cases, the crescent appeared irregular and indistinct. Mitral regurgitation was never severe and did not produce systolic expansion of the left atrium. Case 6 showed multiple irregular thrombi. The aorta was small and the coronary arteries appeared normal. A pericardial effusion was not present in any of these patients.

\section{Discussion}

Right ventricular endomyocardial fibrosis presents with distinctive clinical findings (Ball et al., 1954; Abrahams, 1962; Somers et al., 1968). But left ventricular endomyocardial fibrosis has few distinctive signs by which it can be differentiated from rheumatic heart disease and left ventriculography is essential for the diagnosis. A clinical syndrome as described by Fowler and Somers (1968) is characterised by an early mitral systolic murmur, a third heart sound, and often an opening snap ascribed to a mobile anterior cusp. Fibrosis often affects the apex of the left ventricle and the posterior wall (Davies and Ball, 1955; Connor et al., 1967, 1968). The posterior cusp of the mitral valve may become adherent to the fibrotic scar in the posterior left ventricular wall. The anterior cusp usually shows no evidence of thickening, shrinkage, or scarring; its papillary muscle is normal even though it is inserted into the apical scar. Because of these unique pathological features, mitral regurgitation occurs only in the first half of systole as the normal anterior cusp maintains competence in late systole. The opening snap produced by this normal anterior cusp was present in 6 of the 12 patients in the series reported by Fowler and Somers (1968), but we did not find this clinical sign in any of our patients. Moreover, 2 of our patients had a pansystolic murmur with late systolic decrescendo and they had moderate mitral regurgitation on left ventriculography. These features may well have been the result of a more advanced stage of left ventricular fibrosis in our patients.

Right ventricular endomyocardial fibrosis is often associated with aneurysmal dilatation of the right atrium caused by the conspicuously raised right atrial pressure. Even though the left atrial pressure was raised to very high levels, only mild to moderate left atrial enlargement was present in our patients. Moreover, unlike isolated right ventricular endomyocardial fibrosis, right ventricular involvement in biventricular endomyocardial fibrosis seems to be associated with only mild to moderate right atrial dilatation. Intracardiac calcification when present was diffuse and did not have any characteristic distribution. Calcification was seen only in patients with a severe form of the disease. Since Cockshott et al. (1967) described this abnormality, reports of such gross calcification involving both ventricles have rarely been published.

One other feature in 6 of our patients was a disparity between the clinical, electrocardiographic, and radiological signs, and the degree of pulmonary hypertension. Five patients had severe pulmonary hypertension as shown by a pulmonary vascular resistance greater than 7.5 units. This was not obvious clinically nor did the electrocardiogram show right axis deviation or right ventricular hypertrophy. The chest $x$-ray showed only slight prominence of the main pulmonary artery segment in 2 of them. Inconspicuous dilatation of the pulmonary artery may be an indication of involvement of the right ventricle by the same pathological process or the effect of a persistently low cardiac output. Pulmonary hypertension was always accompanied by a very high left ventricular end-diastolic pressure. A raised left ventricular end-diastolic 
pressure had no relation to the degree of mitral regurgitation. Four of our patients with trivial to mild mitral regurgitation had severe pulmonary hypertension. It appears that the restriction of ventricular filling by endocardial fibrosis and the consequent rise in left ventricular diastolic pressure lead to the development of pulmonary hypertension.

From the foregoing discussion it is evident that the absence of a prominent apical impulse, the presence of a loud third heart sound over the apex, an apical early systolic murmur with late systolic decrescendo, and moderate left atrial enlargement with pronounced pulmonary venous congestion on the $x$-ray film, are characteristic of left ventricular endomyocardial fibrosis. Unlike rheumatic mitral regurgitation, the clinical symptoms and pulmonary venous congestion are out of proportion to the amount of mitral regurgitation. Even though some of these physical signs may help in differentiating left-sided endomyocardial fibrosis from rheumatic mitral regurgitation, this cannot be done with certainty without left ventriculography.

In this series we have found some patients with near normal cardiovascular findings and others with pronounced cardiomegaly and severe congestive heart failure, representing two ends of the spectrum of endomyocardial fibrosis. It appears that early involvement of the left ventricle with scattered areas of fibrosis in the apical and submitral region can be detected only by cineventriculography. This stage of the disease is followed by progressively increasing endocardial fibrosis and restriction to ventricular filling with rising ventricular end-diastolic pressure and consequent pulmonary hypertension. The involvement of the posterior mitral valve cusps, papillary muscles, and altered contraction sequence produces mitral regurgitation. These changes on the left side are often accompanied by involvement of the right ventricle. The final picture is one of severe congestive heart failure with little response to conventional forms of treatment.

\section{References}

Abrahams, D. G. (1962). Endomyocardial fibrosis of the right ventricle. Quarterly fournal of Medicine, 31, 1.

Ball, J. D., Williams, A. W., and Davies, J. N. P. (1954). Endomyocardial fibrosis. Lancet, 1, 1049.

Cockshott, W. P., Saric, S., and Ikeme, A. C. (1967). Radiological findings in endomyocardial fibrosis. Circulation, 35, 913.

Connor, D. H., Somers, K., Hutt, M. S. R., Manion, W. C., and D'Arbela, P. G. (1967). Endomyocardial fibrosis in Uganda, Part I. American Heart Fournal, 74, 687.

Connor, D. H., Somers, K., Hutt, M. S. R., Manion, W. C., and D'Arbela, P. G. (1968). Endomyocardial fibrosis in Uganda, Part II. American Heart fournal, 75, 107.

Davies, J. N. P., and Ball, J. D. (1955). Pathology of endomyocardial fibrosis in Uganda. British Heart fournal, 17, 337.

Fowler, J., and Somers, K. (1968). Left ventricular endomyocardial fibrosis and mitral incompetence. Lancet, 1, 227.

Kinare, S. G., and Deshpande, D. H. (1965). Endomyocardial fibrosis. Indian Fournal of Medical Sciences, 19, 63.

Mehrothra, A. N., Maheswari, H. B., Khosla, S. N., and Kumar, S. (1964). Endomyocardial fibrosis. Fournal of the Association of Physicians of India, 12, 845.

Reddy, C. R. R. M., Murthy, V. S. N., and Rao, A. N. R. (1969). Endomyocardial fibrosis. Fournal of the Indian Medical Association, 53, 17.

Reddy, C. R. R. M., Parvathi, G., and Rao, N. R. (1970). Pathology of cardiomyopathy from South India. British Heart fournal, 32, 226.

Reddy, D. J., Omer, S., Prabhakar, V., Rao, P. S. S., and Rao, K. S. (1965). Endomyocardial fibrosis. Fournal of the Indian Medical Association, 45, 440.

Samuel, I., and Anklesaria, X. J. (1960). Endomyocardial fibrosis in South India. Indian fournal of Pathology and Bacteriology, 3, 157.

Shah, V. V., Goodluck, P. L., and Mehtha, A. C. (1962). Cardiomyopathy. Indian Heart fournal, 14, 70.

Somers, K., Brenton, D. P., D'Arbela, P. G., Fowler, J. M., Kanyerezi, B. R., and Sood, N. K. (1968). Haemodynamic features of severe endomyocardial fibrosis of right ventricle, including comparison with constrictive pericarditis. British Heart Fournal, 30, 322.

Requests for reprints to Dr. George Cherian, Department of Cardiology, Christian Medical College and Hospital, P.O. Box No. 3, Vellore 632004, Tamil Nadu, India. 